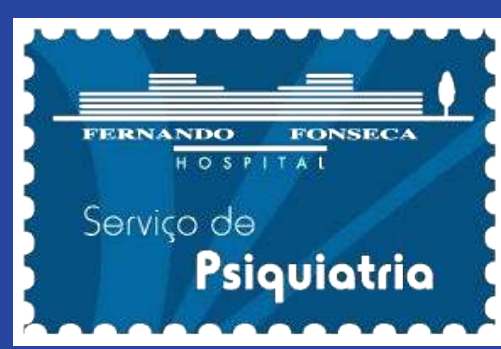

$\Gamma_{19^{\text {TH }} \text { WPA WORLD }}$ CONGRESS OF PSYCHIATRY LISBON, 21-24 AUGUST, 2019

\section{A CASE OF DELIRIUM WITH CATATONIC FEATURES}

\section{CATIVO, Catarina; SERRANO, Raquel; GONÇALVES, Patrícia; COSTA-PEDRO, João; DIAS, Manuel;}

BORJA-SANTOS, Nuno; MAIA, Teresa.

Department of Psychiatry, Hospital Prof. Dr. Fernando Fonseca, Amadora, Portugal.

\section{INTRODUCTION}

While catatonia is characterized by motor symptoms and behavioural signs and delirium is mostly defined by a disturbed sensorium, they may have overlapping symptoms. These include altered awareness and behaviour changes. Although DSM- 5 considers that catatonia does not present with altered sensorium and excludes the possibility of its co-occurrence with delirium, this finding is common in clinical context. Considering the differences in treatment and prognosis of these 2 syndromes, it is of great clinical significance to focus on their relationship.

The authors aim to report a case of delirium with catatonic features and discuss the implications of conceptualizing this subtype of delirium.

\section{MATERIALS AND METHODS}

Case report and non-systematic review through literature research in PubMed/Medline database, using the key-words: catatonia and delirium

\section{RESULTS}

\section{CASE REPORT}

Medical history: 37 year-old female, living with her husband and 11 year-old son, currently unemployed, undergoing professional training.

No personal or family psychiatric history

No history of substance abuse

Diagnosed with HIV infection 12 years prior, currently undergoing treatment with ART with Dolutegravir+Lamivudine+Abacavir, which she thoroughly follows. Regular infectious diseases consultations with no recent changes in medication and with viral load nearly undetectable.

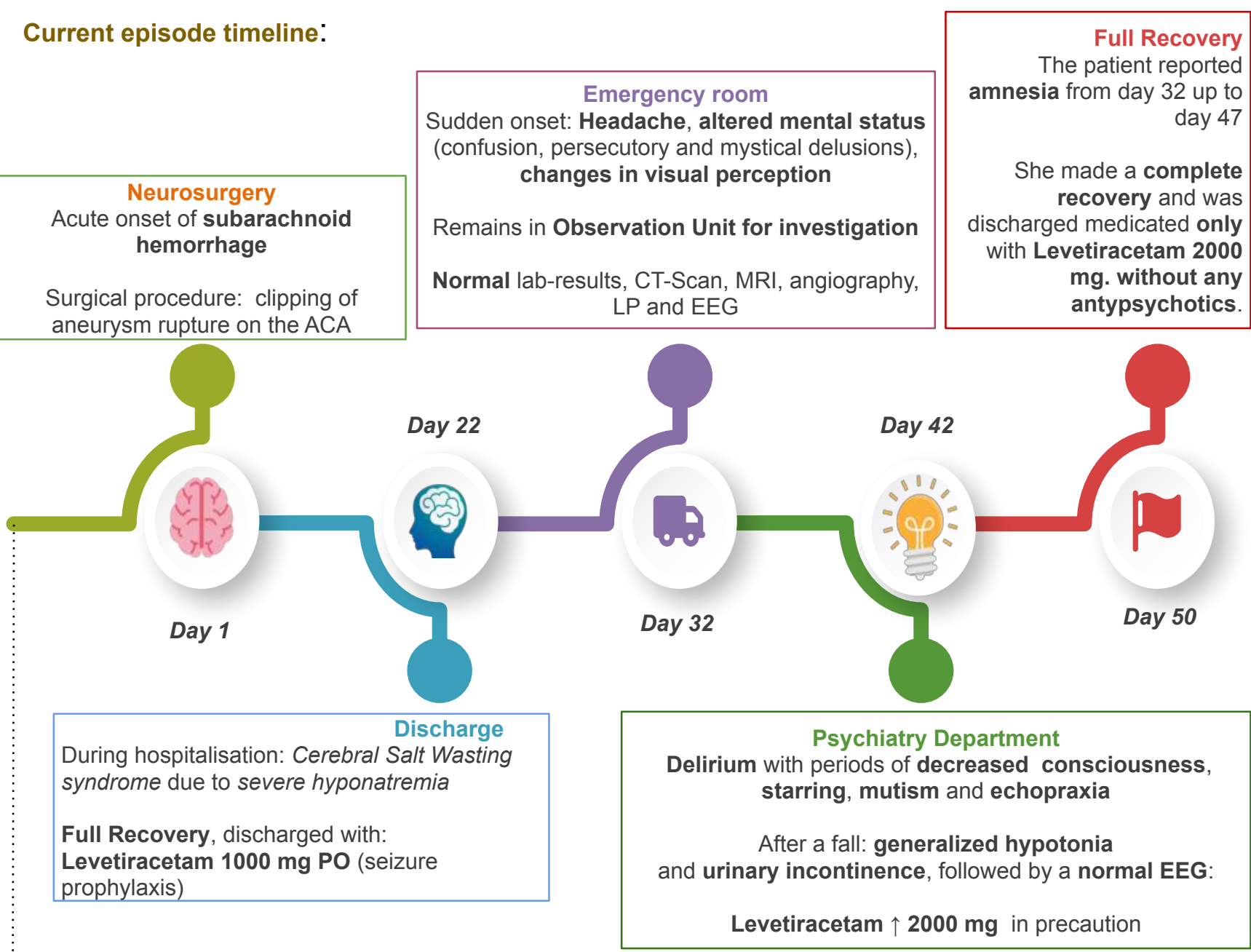

Emergency Room

Forgot to take Levetiracetam for 3 day

Fund laying on the floor in mutism and was brought to the ER.

Clinical picture closely resembling the previous episode with Delirium with catatonic

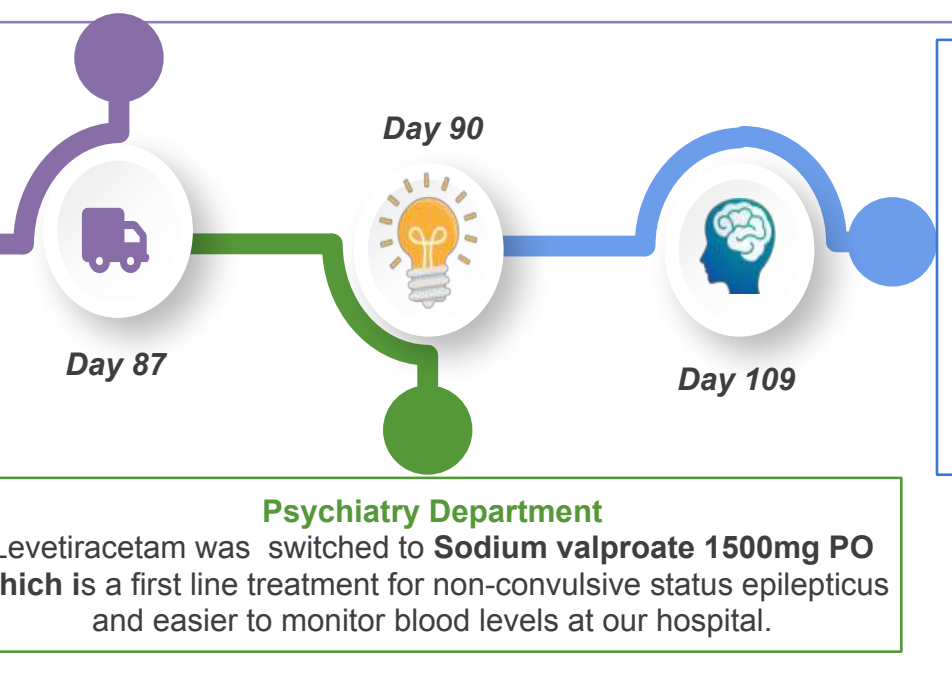

\section{LITERATURE REVIEW AND DISCUSSION}

Studies of noncognitive features of delirium, focusing on motor activity, have led to the conceptualization of the hypoactive, hyperactive, and mixed subtypes. ${ }^{2}$

Some motor and behavioral aspects of delirium appear to overlap with the signs of catatonia (Table 1).

\begin{tabular}{|c|c|c|}
\cline { 3 - 3 } \multicolumn{2}{l|}{} & $\begin{array}{c}\text { Catatonia } \\
\text { (Bush-Francis Catatonia Rating Scale) }\end{array}$ \\
\hline $\begin{array}{c}\text { Hypoactive delirium } \\
(\mathrm{DSM}-\mathrm{V})\end{array}$ & $\begin{array}{c}\text { Psychomotor retardation, } \\
\text { sluggishness, lethargy, stupor }\end{array}$ & $\begin{array}{c}\text { Immobility, withdrawal, } \\
\text { posturing, mutism, negativism }\end{array}$ \\
\hline $\begin{array}{c}\text { Hyperactive delirium } \\
(\mathrm{DSM}-\mathrm{V})\end{array}$ & $\begin{array}{c}\text { Increased psychomotor activity, } \\
\text { mood lability, agitation, refusal } \\
\text { do cooperate }\end{array}$ & $\begin{array}{c}\text { Impulsivity, mannerisms, } \\
\text { excitement, combativeness }\end{array}$ \\
\hline
\end{tabular}

Table 1 - The relationship between delirium subtypes (DSM-V) and Catatonia signs (BFCRS).

DSM-5 specifies that catatonia can't be diagnosed in the presence of delirium, since it must occur in clear consciousnesses, however the evidence for this requirement is not yet solid and in clinical context they often coexist ${ }^{4}$, most prominently in the hypoactive motoric subtype of delirium (figure 1 ). ${ }^{2}$

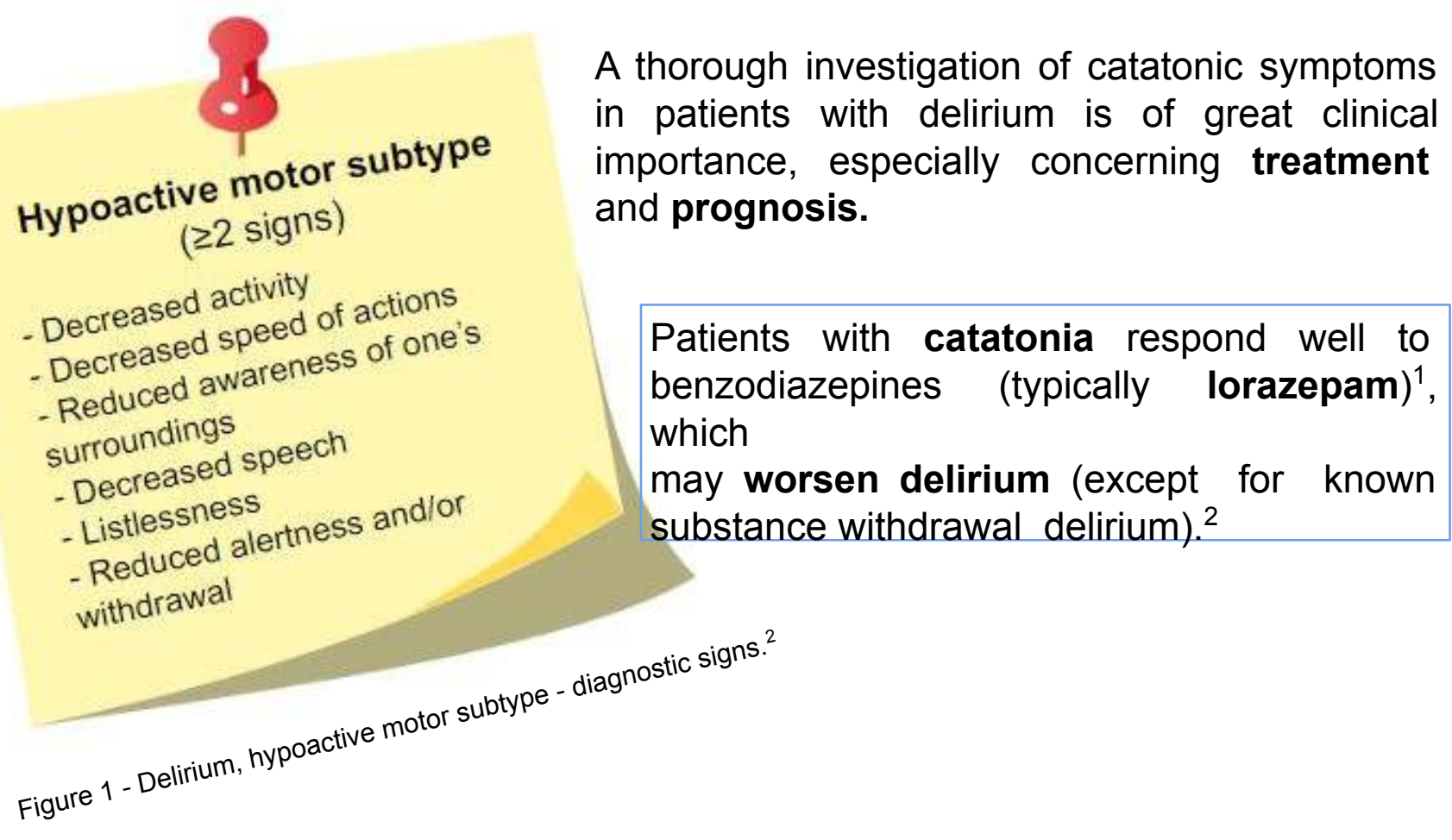

As an adjuvant in the treatment of delirium, antipsychotics are often used, but they may worsen catatonia or precipitate a lethal or malignant form similar to neuroleptic malignant syndrome. ${ }^{1}$

Either in the presence of catatonia or delirium, it is of the utmost importance to understand the underlying cause to choose appropriate treatment.

In this clinical case we assumed the diagnosis of non-convulsive status epilepticus, considering the abrupt onset after neurosurgery intervention, amnesia absence of family/personal psychiatric history, no substance abuse and rapid and total remission after anticonvulsivant therapy, without antipsychotics.

Even if several isolated EEG were normal, longer EEG monitoring ( $>24 \mathrm{~h}$ ), IV anticonvulsivant trial during the exam, or electrodes with increased sensibility (eg: sphenoidal), are often necessary to reveal the characteristic EEG pattern. ${ }^{8}$

\section{CONCLUSION}

This case is a clear example that the relationship between catatonia and delirium goes beyond simple overlap, leading to the conceptualization of the new subtypes of delirium, the hypoactive motor subtype being the most prominent as an equivalent of delirium with catatonic features.

The debate over whether catatonia and delirium are separate entities, if they exist on a spectrum or if they can co-exist in a catatonic subtype of delirium, has important implications in selecting treatment and predicting prognosis. It may also provide further insight in understanding the subtyping of delirium and also in understanding its neurobiological foundations. 